\title{
Improvement of Coding for Solar Radiation Forecasting in Dili Timor Leste-A WRF Case Study
}

\author{
Jose Manuel Soares de Araujo \\ Electrical and Electronic Engineering Division, Graduate School of Natural Science and Technology, Gifu University, Gifu, Japan \\ Email: isakhar.inside13@gmail.com
}

How to cite this paper: de Araujo, J.M.S. (2021) Improvement of Coding for Solar Radiation Forecasting in Dili Timor LesteA WRF Case Study. Journal of Power and Energy Engineering, 9, 7-20. https://doi.org/10.4236/jpee.2021.92002

Received: July 10, 2020

Accepted: February 21, 2021

Published: February 24, 2021

Copyright ( 2021 by author(s) and Scientific Research Publishing Inc. This work is licensed under the Creative Commons Attribution International License (CC BY 4.0).

http://creativecommons.org/licenses/by/4.0/

\begin{abstract}
This paper investigates the accuracy of weather research and forecasting by improving coding for solar radiation forecasting for location in Dili Timor Leste. Weather Research and Forecasting (WRF) model version 3.9.1 is used in this study for improvement purposes. The shortwave coding of WRF is used to improve in order to decrease error simulation. The importance of improving WRF coding at a specific region will reduce the bias and root mean square root when comparing to the observed data. This study uses high resolution based on the WRF modeling to stabilize the performance of forecasting. The decrease in error performance will be expected to enhance the value of renewable energy. The results show the root mean square error of the WRF default is $233 \mathrm{~W} / \mathrm{m}^{2}$ higher compared to $205 \mathrm{~W} / \mathrm{m}^{2}$ from the WRF improvement model. In addition, the Mean Bias Error (MBE) of the WRF default is obtained value 0.06 higher than 0.03 from the WRF improvement in rainy days. Meanwhile, on sunny days, the performance Root Mean Square Error (RMSE) of WRF default is $327 \mathrm{~W} / \mathrm{m}^{2}$ higher than $223 \mathrm{~W} / \mathrm{m}^{2}$ from the WRF improvement. The MBE of WRF improvement obtained 0.13 lower compared to 0.21 of WRF default coding. Finally, this study concludes that improving the shortwave code under the WRF model can decrease the error performance of the WRF simulation for local weather forecasting.
\end{abstract}

\section{Keywords}

Shortwave Radiation, Solar Radiation, Timor Leste, WRF Code Improvement

\section{Introduction}

As a tropical region, Timor Leste is one of the challenging countries in the world 
to predict, and particularly forecasting of cloud cover is harder and more difficult [1]. Accurate forecasting of solar radiation influences the usage of solar resources as the most active resource for renewable energy and could help operators to reduce the cost for the benefit of forecasting for energy markets [2]. In recent years the implementation of renewable energy has been increasing rapidly, however increasing the distribution of renewable energy means also increasing the reliable energy generation forecast for implementation in electricity grid connection. Somehow unexpected, sometimes large errors in solar irradiance forecasting may lead to the performance of reliable energy generation. Based on this, a study of improvement of forecasting should be taken more carefully in order to perform better and a significant irradiance forecast. In addition, the complexity of local terrain, imperfect measured data, and uncertain physics of cloud formation may also lead to the performance of forecasting.

Numerical Weather Prediction (NWP) [3] model is a physical method which mostly used by researchers around the world to perform the most accurate solar irradiance forecasting from hourly to daily. Imperfections of physics parameterization in NWP may lead to the imperfection of the model. The implementation of an NWP has been considered very useful in the planning of forecasting generation output. However, in some cases of studies, forecasting obtained from the NWP based on input data may contain errors. Therefore, the improvement of NWP is necessary for the optimization of forecasting. In particular, there are some limitations which unavoidable for predictions such as impacts on the environment, observation instruments incomplete, and technical skills that may cause an error [4].

Many studies have improved by calculating efficiency, improvement in the parameter optimization, high-speed application and supercomputer, and resolution of the model. Their results contributed to observation skills, however, the NWP model is still uneasy to deal with the operational demand for solar radiation forecasting [5]. Many companies have customized their NWP model to forecast solar irradiance based on the principles of geophysical fluids dynamics and thermodynamics for more than ten days. NWP models are the main basis of yield forecast with the time range of 48 hours time horizon for decision making and grid connection. It uses initial and boundary conditions for the model to run the atmospheric simulation [6].

Several articles have demonstrated the improvement of NWP for prediction purposes. Kim and Clarkson [7] presented a study of developing and improving Global Horizontal Irradiance (GHI) and Direct Normal Irradiance (DNI) using the Weather Research and Forecasting (WRF) as the NWP model for location in Arizona. They showed that during the 2011 NAM season, the model performed poorly which likely has related to the frequent. Alessandrini et al. [8] applied the European Centre for Medium-Range Forecast (ECMWF) as an NWP model to predict wind power at a three-hourly interval out to 72 hours. Deppe et al. [9] applied an ensemble NWP model to forecast wind at a one-hour interval out to 
48 hours. Lorenz et al. (2009a) [10] evaluated the GHI forecast using several NWP in Europe. Overall, their results showed values of relative RMSE were about 40\%. Ewan et al. (2006) [11] evaluated the MM5 as NWP for modeling the GHI forecast in Germany with time up to 48 hours. Their study showed that the values of relative RMSE were about $50 \%$.

The main contribution of this study is to compare the improvement coding of the WRF model and WRF default coding for solar radiation forecasting which is located in Dili Timor Leste. The results of improvement and default WRF model simulation were used to validate against ground station single point for local understanding. The model configuration and parameter setting of WRF nesting model simulation for of $1 \times 1 \mathrm{~km}$ spatial resolution for a period of ten days where five days were on a rainy day and the other five days were sunny. The five days of rainy days from $1^{\text {st }}$ to $5^{\text {th }}$ June 2015 and the other five days of sunny days from $1^{\text {st }}$ to $31^{\text {st }}$ October 2015 were used for validation in this study with locally observed data. Finally, this study proposes the physics parameterization of the improvement WRF coding can be used to reduce and decrease the uncertainties result of the NWP itself and improve the performance for a great significance result.

The structure of this work is organized as follows: Section 2 describes sources data used in this paper and the study region. The implementations of WRF model simulation coding and two error evaluation metrics are introduce in Section 3. The results of the performance of the default and improvement, error analysis and comparison data are presented in Section 4. Discussion of this study is presented in Section 5. Finally, Section 6 describes a brief summary of study conclusions.

\section{Sources Data and Study Region}

The hourly solar radiation on sunny days from $1^{\text {st }}$ to $5^{\text {th }}$ October 2015 and rainy days from $1^{\text {st }}$ to $5^{\text {th }}$ June 2015 were obtained from an installed weather station in Hera, Dili Timor Leste [12]. These data are used as observational analysis for solar radiation. Meanwhile, $1 \mathrm{deg} \times 1 \mathrm{deg}$ grid data downloaded from the national center for environmental prediction (NCEP) website

(https://rda.ucar.edu/datasets/ds083.2/) were used as input data in the WRF model to run solar radiation simulation. Figure 1 is Hera city which located around $12.4 \mathrm{~km}$ in the east of Dili. This area was chosen as a study region as it has a weather station and potential of high solar radiation for prediction purposes in order to apply for large solar PV panel installation. This simulation used Linux Ubuntu 16.04 LTS (Long Term Support) 64 bit operating running on Intel(R) Core(TM) i7-7700 CPU @ 3.60 GHz computer with 8 GB of RAM.

\section{Methodology}

\subsection{WRF Model}

In this study, the Weather Research and Forecasting-Advanced Research WRF 


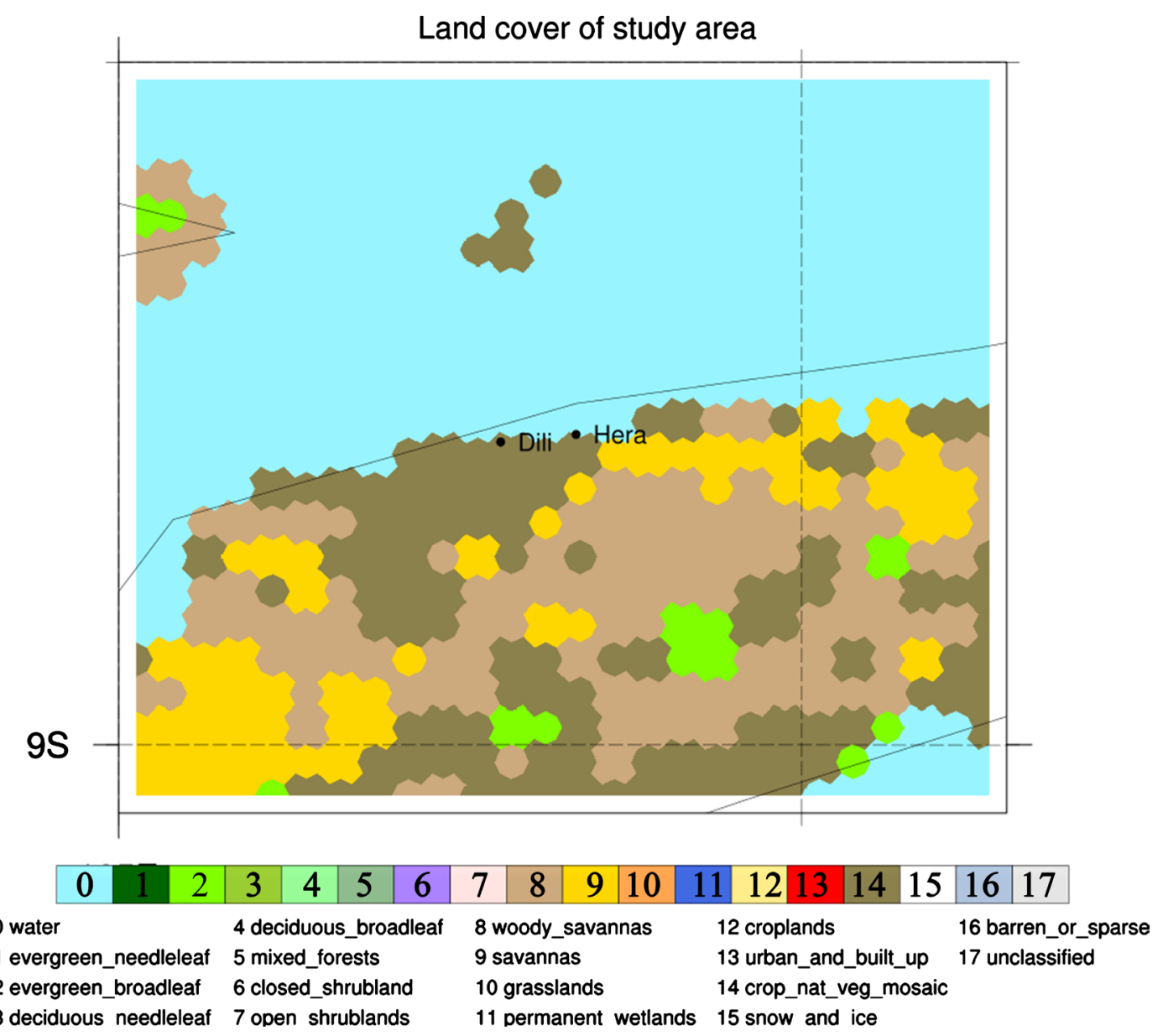

Figure 1. Land cover of study area used in this study [12].

(WRF-ARW) model version 3.9.1 [13] was used to simulate solar radiation on sunny and rainy days over Hera area in Dili Timor Leste. The WRF model is widely and very well-known used by many researchers around the world to make a prediction. This model is a numerical mesoscale meteorological model consisting of the numerical scheme, dynamics, physics, and non-hydrostatic primitive equations in the atmosphere. This model conducted a simulation using initial and boundary conditions by applying NCEP analysis operational data at 1 $\operatorname{deg} \times 1$ deg resolution [14]. These analysis data are 6-hourly Global Data Assimilation System (GDAS) are collected from the Global Telecommunications System (GTS) and boundary condition data includes the landuse of the United States Geographical System (USGS) 24 category terrestrial, the elevation of terrain in 2 minutes and vegetation fraction in 10 minutes data. In addition, this model provides information regarding albedo, Direct Normal Irradiance (DNI), Diffuse Irradiance (DIF), Global Horizontal Irradiance (GHI), longitude and latitude, cos zenith, topography, land cover, sea surface temperature, wind speed, pressure, relative humidity, etc.

The high horizontal resolution of $9 \mathrm{~km}, 3 \mathrm{~km}$, and $1 \mathrm{~km}$ were using in a three-two nested domain in this study. Figure 2 and Table 1 are three initial conditions 


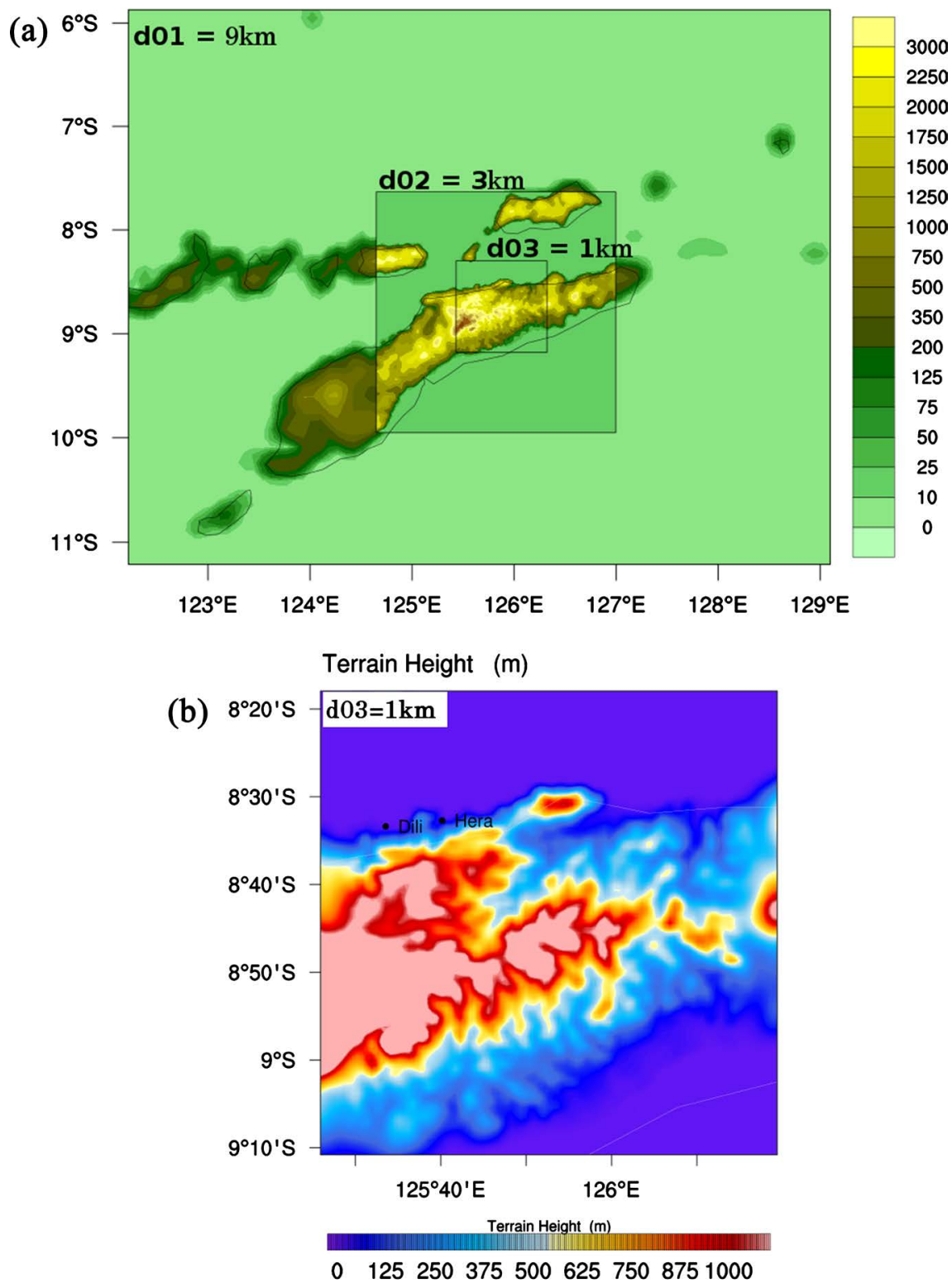

Figure 2. (a) Plotting of three two way nesting domain; (b) View of domain 03 at $1 \mathrm{~km}$ resolution. Data of domain d03 were used for comparison purposes [12].

and main characteristics using in this simulation. This simulation experiment uses Thompson and Eidhammer (2014) [15] as microphysics. This scheme uses the cloud, double moment rain, cloud condensation which suitable for a cloud-resolving grid in warm conditions. RRTMG radiation scheme [16] was used in this present study for shortwave and long wave radiation. This scheme can resolve clouds and clouds fraction and suites for modeling climate in regional. Yonsei University Planetary Boundary Layer (PBL) scheme [17] was adopted to consider non-local fluxes through a parameterized between interaction land surface and PBL due to variations of the surface heat flux. Noah LSM was used in this simulation for the land surface model [18]. Plotting for its grid point uses NCL NCARG version 6.5.0 [19]. In this study, the shortwave coding 
Table 1. More WRF parameter configurations used in this simulation.

\begin{tabular}{cc}
\hline Period & $\begin{array}{c}\text { Rainy days: } 1^{\text {st }} \text { to } 5^{\text {th }} \text { June } 2015 \\
\text { Sunny days: } 1^{\text {st }} \text { to } 5^{\text {th }} \text { October } 2015\end{array}$ \\
\hline Input data & NCEP FNL $\left(6\right.$-hourly, $\left.1^{\circ} \times 1^{\circ}\right)$ \\
\hline Nesting & Two-way nesting \\
\hline Map projection & Mercator \\
\hline Domain & Domain 1, d01 $(9 \mathrm{~km}, 86 \times 68$ grids $)$ \\
& Domain 2, d02 $(3 \mathrm{~km}, 88 \times 88$ grids $)$ \\
Domain 3, d03 $(1 \mathrm{~km}, 100 \times 100$ grids $)$
\end{tabular}

file under "phys/" folder of WRF default model was used to improve for better understanding. Table 2 shows the details of the configuration of WRF default and improvement coding for shortwave radiation where bold letter indicating enhance coding.

Solar radiation which reaches the surface of the earth is formed from solar direct and solar diffuse. Solar direct is the amount of radiation coming directly from the sun and reaches the surface of the earth. Meanwhile, solar diffuse is the scatter radiation on the sky which reaches to earth's surface. The amount of solar radiation reaches a given location varies in time because of the variation distance between sun and earth. It is greater when the sun closer to the earth and when the sun is located on the top of the atmosphere. As mentioned before, the sun movement also determines by the time such as local time, apparent solar time, universal time, Equation of Time (EOT), and Green Meridian Time (GMT). However, some variables are considered very important and become as main causes for determining the available solar radiation. These variables are composed of the day (Julian), albedo, latitude (xxlat), longitude (xlong), altitude, solar azimuth (csza), solar constant (soltop), zenith angle (coszen), solar declination (declin), and solar hour angle (hrang). The sun's angle is always dependent on latitude including the time of day and year where during the daytime, sunrise increase until noontime and decreases until sunset. In this present study, the shortwave radiation of WRF default code under "Phys" does not contain any information regarding solar altitude. Solar altitude is the elevation angle on the horizon and has been considered as one of the parameters to determine solar 
Table 2. WRF default and improvement shortwave code.

\begin{tabular}{|c|c|}
\hline Default WRF shortwave code & Improvement of WRF shortwave code \\
\hline REAL :: diffuse_frac, corr_fac, csza_slp & REAL:: diffuse_frac, corr_fac, csza_slp \\
\hline GSW $=0.0$ & $\mathrm{GSW}=0.0$ \\
\hline bext $340=5 . \mathrm{E}-6$ & bext $340=5 . \mathrm{E}-6$ \\
\hline bexth $20=5 . E-6$ & bexth $20=5 . E-6$ \\
\hline SOLTOP=SOLCON & SOLTOP=SOLCON \\
\hline if (present(coszen)) then & if (present $(\operatorname{coszen}))$ then \\
\hline $\operatorname{csza}=\operatorname{coszen}$ & $\operatorname{csza}=\operatorname{coszen}$ \\
\hline else & else \\
\hline xt24 $=\bmod (x t i m e+$ radfr & $\mathrm{xt} 24=\bmod (\mathrm{xtime}+\mathrm{radfrq}$ \\
\hline$\left.{ }^{*} 0.5,1440.\right)+$ eot & $\left.{ }^{\star} 0.5,1440.\right)+$ eot \\
\hline tloctm $=$ gmt + xt24/60. + xlong $/ 15$ & tloctm $=$ gmt $+\mathrm{xt} 24 / 60 .+\mathrm{xlong} / 15$ \\
\hline hrang $=15 .^{*}($ tloctm- & hrang $=15 .{ }^{*}$ (tloctm- \\
\hline 12.)* degrad & 12.) $*$ degrad \\
\hline \multirow[t]{2}{*}{ xxlat $=$ xlat $*$ degrad } & xxlat $=$ xlat $*$ degrad \\
\hline & $\operatorname{csza}=\sin (x x l a t) * \sin ($ declin $)$ \\
\hline $\operatorname{csza}=\sin (x x l a t) *$ & $+\cos (\mathrm{xxlat}){ }^{*} \cos ($ declin $)$ \\
\hline $\sin ($ declin $)+$ & ${ }^{*} \cos ($ hrang $)$ \\
\hline \multicolumn{2}{|l|}{$\cos ($ xxlat $) * \cos ($ declin $)$} \\
\hline \multirow[t]{2}{*}{${ }^{*} \cos ($ hrang $)$} & $\operatorname{cszm}=\left(\cos (\text { declin })^{*} \cos (x x l a t) * \tan (\right.$ declin $)+\sin (x x$ \\
\hline & lat $)^{*} \cos ($ hrang $\left.)\right) / \cos (\operatorname{csza})$ \\
\hline \multicolumn{2}{|l|}{ end if } \\
\hline & end if \\
\hline \multirow[t]{2}{*}{$\mathrm{XMU}=\mathrm{csza}$} & $\mathrm{XMU}=\mathrm{csza}$ \\
\hline & $\mathrm{XMM}=\mathrm{cszm}$ \\
\hline \multicolumn{2}{|l|}{$\operatorname{SDOWN}(1)=$ SOLTOP $^{*} \mathrm{XMU}$} \\
\hline & $\begin{array}{l}\text { SDOWN }(1)=\text { SOLTOP }^{*}\left(1+0.03344^{*} \cos \left(0.9856^{*} \text { ju }\right.\right. \\
\text { lian-2.72) }) * \sin (\mathrm{XMU})-\cos (\mathrm{XMM})\end{array}$ \\
\hline \multirow[t]{2}{*}{$\mathrm{GSW}=(1-\mathrm{ALBEDO}) * \operatorname{SDOWN}(\mathrm{kte}+1)$} & \\
\hline & $\mathrm{GSW}=(1-\mathrm{ALBEDO}) * \operatorname{SDOWN}(\mathrm{kte}+1)$ \\
\hline
\end{tabular}

Where: $\mathrm{xt} 24=$ the fractional part of simulation days plus half of radiation; $\mathrm{xtime}=$ forecast time in minute; eot $=$ equations of time; radt = radiation; tloctm = name of the variable apparent solar time (AST); hrang = variable name indicating solar hour angle; $x x l a t=$ variable name indicating latitude; $x l o n g=$ variable name indicating longitude; declin = variables name indicating declination; $\mathrm{XMU}=\mathrm{csza}=$ variable name indicating solar azimuth; $\mathrm{XMM=cszm}=$ variable name indicating solar altitude; julian = variable name indicating day of the year; 1 -ALBEDO = full reflect of albedo; SDOWN = variable name indicating solar top; kte = tile vertical end; GSW = ground short wave.

power from the sun. Based on this parameter, the shortwave radiation file from the WRF model is used to add the equation of solar altitude for improvement purposes of solar radiation in this study.

\subsection{Error Metrics}

The two equations from David et al. [20] such as root mean square error (RMSE) and mean bias error (MBE) were used to evaluate accuracy between the observed data with the simulated data. These two error metrics are defined as below; 


$$
\begin{aligned}
\text { RMSE } & =\sqrt{\frac{1}{n} \cdot \sum_{i=1}^{n}\left(\text { pred }_{i}-\text { obs }_{i}\right)^{2}} \\
\text { MBE } & =\frac{1}{n} \cdot \sum_{i=1}^{n}\left(\text { pred }_{i}-o b s_{i}\right)
\end{aligned}
$$

where pred represented results of the WRF, obs represented Dili weather station observed data, and $n$ is the number of the time step. All error estimation applying values of hourly for the considered period. MBE will quantify and detect if the model will give overestimation $(\mathrm{MBE}>0)$ or underestimation $(\mathrm{MBE}<0)$. On the other hand, error distribution will be counted by RMSE error metric.

\section{Results}

This section discusses the results of the model comparison between WRF default and improving code of solar radiation, cloud cover from 1 to $6 \mathrm{~km}$ above ground level (a.g.l) including two error metrics analysis. Figures 3(a)-(f) showed the results of cloud cover above $1 \mathrm{~km}$ to $6 \mathrm{~km}$ above ground level from the default and improvement code on rainy days. Cloud cover from 1 to $6 \mathrm{~km}$ height above ground level was chosen to analyze the performance of the cloud exist because no clouds were observed from $7 \mathrm{~km}$ height. The blue line represented WRF default data and the red line represented the WRF improvement result. This study showed some interesting values regarding the cloud presence in five days rainy season. Small clouds around 80,40 , and $90 \mathrm{~kg} / \mathrm{m}^{3}$ were observed in $1^{\text {st }}, 2^{\text {nd }}$, and $3^{\text {rd }}$ days in $1 \mathrm{~km}$ a.g.l. Meanwhile, clouds values from 10 to $460 \mathrm{~kg} / \mathrm{m}^{3}$ were mostly observed in the $4^{\text {th }}$ and $5^{\text {th }}$ days. A large number of clouds improving about $860 \mathrm{~kg} / \mathrm{m}^{3}$ at $2 \mathrm{~km}$ a.g.l on the $5^{\text {th }}$ day. No clouds in the $1^{\text {st }}$ day at $1 \mathrm{~km}$ of improvement WRF coding, clouds were started increasing in 2nd and 3rd days about 220 and $30 \mathrm{~kg} / \mathrm{m}^{3}$ which means that the decreasing of the cloud of improvement code. $4^{\text {th }}$ and $5^{\text {th }}$ day showed mostly increasing cloud existence as it was observed about 350 and $860 \mathrm{~kg} / \mathrm{m}^{3}$.

No clouds found at $3 \mathrm{~km}$ a.g.l from the default and improvement code in the $1^{\text {st }}$ and $4^{\text {th }}$ days. Clouds were found decreasing in the $2^{\text {nd }}$ and $3^{\text {rd }}$ days about 130 and $260 \mathrm{~kg} / \mathrm{m}^{3}$ but increasing about $20 \mathrm{~kg} / \mathrm{m}^{3}$ in different hours. Clouds found a significant increase from 190 to $250 \mathrm{~kg} / \mathrm{m}^{3}$ and 10 to $120 \mathrm{~kg} / \mathrm{m}^{3}$. No clouds were observed at 4, 5, and $6 \mathrm{~km}$ a.g.l on the first day. In addition, no clouds were found in the $3^{\text {rd }}$ and $4^{\text {th }}$ days in $4 \mathrm{~km}$ height. Clouds were observed decreasing about $260 \mathrm{~kg} / \mathrm{m}^{3}$ in some hours but increasing about $200 \mathrm{~kg} / \mathrm{m}^{3}$ in different hours for the $2^{\text {nd }}$ day and $5^{\text {th }}$ days.

Clouds were found a significant increase in the $5 \mathrm{~km}$ a.g.l for the $2^{\text {nd }}$ day from 10 to $380 \mathrm{~kg} / \mathrm{m}^{3}$ at noon time around 11 am to $5 \mathrm{pm}$. No clouds were observed from the $3^{\text {rd }}$ to $5^{\text {th }}$ days at $5 \mathrm{~km}$ height. Same as the $5 \mathrm{~km}$ height, clouds only observed in the second day at $6 \mathrm{~km}$ height increasing from 0 to $240 \mathrm{~kg} / \mathrm{m}^{3}$ in the morning time, but decreasing in the noontime about $320 \mathrm{~kg} / \mathrm{m}^{3}$. The clouds continue increasing in the afternoon time from 20 to $290 \mathrm{~kg} / \mathrm{m}^{3}$ around $5 \mathrm{pm}$. In this present study, no cloud results were plotting on sunny days as it was found 

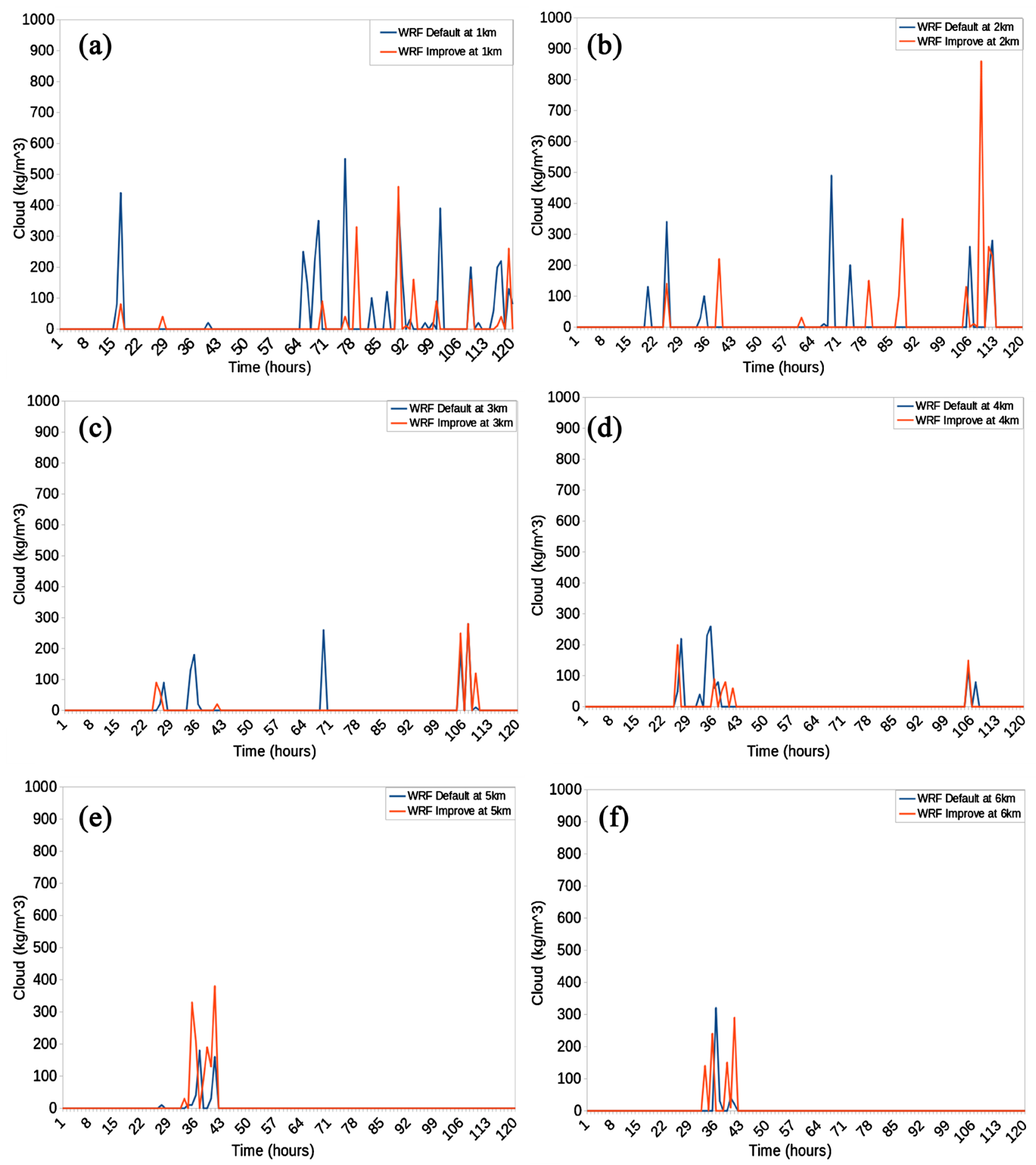

Figure 3. (a) Cloud at $1 \mathrm{~km}$ height; (b) Cloud at $2 \mathrm{~km}$ height; (c) Cloud at $3 \mathrm{~km}$ height; (d) Cloud at $4 \mathrm{~km}$ height; (e) Cloud at 5 $\mathrm{km}$ height; (f) Cloud at $6 \mathrm{~km}$ height.

that almost no clouds were observed from $1 \mathrm{~km}$ to $6 \mathrm{~km}$ height a.g.l.

Figure 4(a) and Figure 4(b) presented results of solar radiation from the default and improvement WRF coding in two seasons, rainy and sunny days, respectively. The blue curve represents the WRF default code, the red curve represents the WRF improvement code, and the green curve represents the 

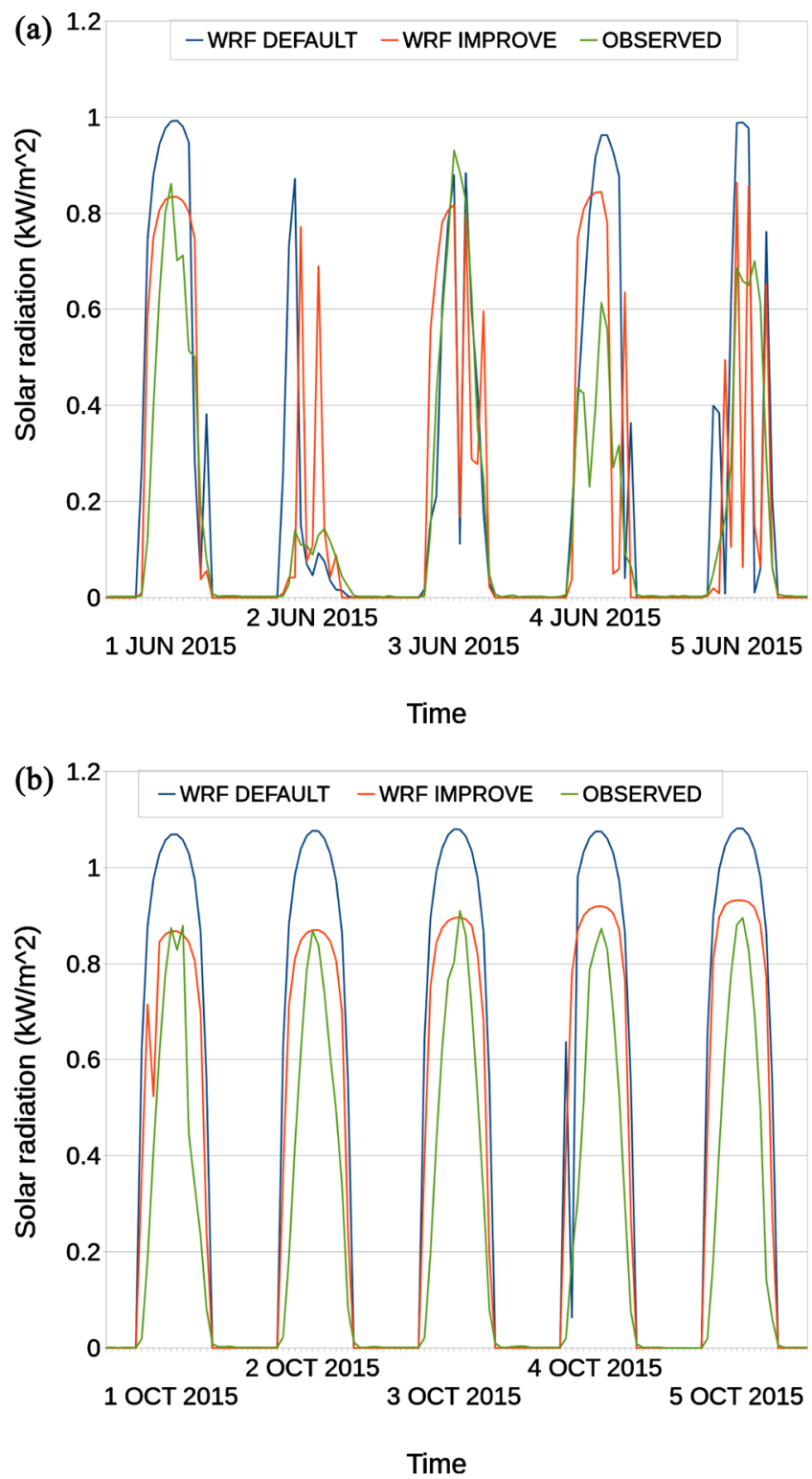

Figure 4. (a) Solar radiation in rainy days, (b) Solar radiation in sunny days.

weather station observed data. Figure 4(a) and Figure 4(b) showed display the good performance to each season in the horizontal resolution which implies that the WRF model was able to provide more accurate solar radiation forecasting. Figure 4(a) shows that on the first day of June of 2015, the solar radiation was decreasing about $263 \mathrm{~W} / \mathrm{m}^{2}$ morning time at $7 \mathrm{am}$, solar radiation around 129 to $158 \mathrm{~W} / \mathrm{m}^{2}$ were found decreasing from 8 am to $4 \mathrm{pm}$. In addition, solar radiation about $326 \mathrm{~W} / \mathrm{m}^{2}$ was observed decreasing at $6 \mathrm{pm}$ on the first day of rainy seasons.

Solar radiation around 78 and $86 \mathrm{~W} / \mathrm{m}^{2}$ were decreasing in $2^{\text {nd }}$ and $3^{\text {rd }}$ day, and about 118 and $124 \mathrm{~W} / \mathrm{m}^{2}$ decreased in $4^{\text {th }}$ and $5^{\text {th }}$ days of June 2015 . Meanwhile, on sunny days, the solar radiation was decreasing about 160 to $201 \mathrm{~W} / \mathrm{m}^{2}$ the $1^{\text {st }}$ and $2^{\text {nd }}$ day of October, solar radiation around 143 to $184 \mathrm{~W} / \mathrm{m}^{2}$ were decreasing in $3^{\text {rd }}$ and $4^{\text {th }}$ day, and about 93 and $149 \mathrm{~W} / \mathrm{m}^{2}$ decreased in the $5^{\text {th }}$ day 
of October 2015. Small solar radiation around $61 \mathrm{~W} / \mathrm{m}^{2}$ was decreasing in $2^{\text {nd }}$ day at noontime and continuously decreasing about 2.79 to $71 \mathrm{~W} / \mathrm{m}^{2}$ in the afternoon time. On the $3^{\text {rd }}$ day, $62.08 \mathrm{~W} / \mathrm{m}^{2}$ were decreasing in the noontime and it had different solar radiation around 9.15 to $307 \mathrm{~W} / \mathrm{m}^{2}$ in the noontime from 2 $\mathrm{pm}$ to $5 \mathrm{pm}$. Solar radiation becomes small about $74.1 \mathrm{~W} / \mathrm{m}^{2}$ in the noontime on the $4^{\text {th }}$ day and it showed the decreasing values around $362 \mathrm{~W} / \mathrm{m}^{2}$ at the $5 \mathrm{pm}$. $124.2 \mathrm{~W} / \mathrm{m}^{2}$ of Solar radiation was found smaller in the noontime on the $5^{\text {th }}$ day. Various decreasing values were still decreasing in the afternoon time around 108 to $145 \mathrm{~W} / \mathrm{m}^{2}$ from $2 \mathrm{pm}$ to $6 \mathrm{pm}$.

Figure 4(b) shows the plotting of solar radiation comparison on sunny days, the solar radiation was decreasing about 160 to $201 \mathrm{~W} / \mathrm{m}^{2}$ the $1^{\text {st }}$ and $2^{\text {nd }}$ day of October, solar radiation around 143 to $184 \mathrm{~W} / \mathrm{m}^{2}$ were decreasing in $3^{\text {rd }}$ and $4^{\text {th }}$ day, and about 93 and $149 \mathrm{~W} / \mathrm{m}^{2}$ decreased in the $5^{\text {th }}$ day of October 2015. The improvement code has tested for two different seasons in Hera, Dili Timor Leste, dry and wet, respectively. The performance improvement was mostly affected in the dry season as it has close results with the observed data. Based on the surface study, it can be analyzed that the influence of the existence of the cloud giving significance affects the performance of solar radiation. In addition, the improvement of solar altitude of the coordinate such as latitude, longitude, altitude also affects the performance of solar radiation forecasting.

The calculation of two error metrics between WRF default and improvement coding for five days solar radiation of sunny and rainy was also presented in this study. The MBE and RMSE were used as criteria for the comparison of the model. The error metrics of RMSE and MBE between default and improvement WRF coding on rainy days are shown in Table 3 . The RMSE of WRF default coding was obtained $233 \mathrm{~W} / \mathrm{m}^{2}$ higher compared to $205 \mathrm{~W} / \mathrm{m}^{2}$ from the WRF improvement coding. In addition, the MBE of default WRF coding was obtained 0.06 higher than 0.03 from the WRF improvement on a rainy day. Meanwhile, for sunny days, the results showed the same condition. Table 4 showed the error metrics of RMSE and MBE between default and improvement WRF coding on sunny days. The RMSE of WRF improvement was obtained $223 \mathrm{~W} / \mathrm{m}^{2}$ lower compared to the $327 \mathrm{~W} / \mathrm{m}^{2}$ from the WRF default coding. In addition, the MBE

Table 3. WRF code default and improvement of rainy day.

\begin{tabular}{ccc}
\hline Variable & MBE & RMSE \\
\hline WRF Default & 0.06 & $233 \mathrm{~W} / \mathrm{m}^{2}$ \\
WRF Improvement & 0.03 & $205 \mathrm{~W} / \mathrm{m}^{2}$ \\
\hline
\end{tabular}

Table 4. WRF code default and improvement of sunny day.

\begin{tabular}{ccc}
\hline Variable & MBE & RMSE \\
\hline WRF Default & 0.21 & $327 \mathrm{~W} / \mathrm{m}^{2}$ \\
WRF Improvement & 0.13 & $223 \mathrm{~W} / \mathrm{m}^{2}$ \\
\hline
\end{tabular}


of sunny days was obtained 0.13 lower compared to 0.21 from the WRF default. Based on these results, it can be analyzed that improving the shortwave radiation code can successfully increase the performance of solar radiation forecasting for the WRF model. The improved values found to be in good agreement with the observed values. In this regard, shortwave radiation improvement coding gives a suitable prediction of solar radiation for local necessary.

\section{Discussions}

Despite the clear understanding of solar radiation forecasting which recorded at a local ground weather station at Hera city, the performance of solar radiation prediction in the present study extremely process for renewable energy and solar radiation applications for the effectiveness and sustainability of an investment. With a care feature selection coding under the WRF model, the shortwave radiation was chosen as the most important variable for improvement at 10 days predictions. The results show that WRF simulation performed the decreasing error performance of solar radiation prediction and the improvement method in this study can be used by other researchers in the field of climate and environment, geophysics sciences, or energy sciences. Moreover, the results present in this study may be interesting for engineers, stakeholders, including solar power investors to make predictions for solar radiation at the sites where local weather stations are not available. In addition, this present study can be used also to determine whether a project is economically suitable in the term of solar power investment.

\section{Conclusions}

In this study, an improvement of WRF coding for shortwave radiation for five days of simulation on sunny and rainy days was conducted in Dili, Timor Leste. High resolution of $1 \mathrm{deg} \times 1 \mathrm{deg}$ of a numerical weather prediction based on the WRF-ARW model was used to simulate ten days of solar radiation. This paper analyzed the frequency of clouds presence over the region from $1^{\text {st }}$ to $5^{\text {th }}$ June and $1^{\text {st }}$ to $5^{\text {th }}$ October 2015 which affected the solar radiation forecasting. The results of solar radiation forecasting were comparing with the local weather station data for further understanding. After improvement the shortwave coding under WRF physics coding, the result of solar radiation for five days of sunny and rainy days are getting close to observed data in the early morning time and in the afternoon time. In addition, improving the shortwave code includes the microphysics size and number distribution code of three particle types: cloud water, cloud ice, and rain affected the decreasing and increasing of solar irradiance. This study showed that the significant decrease of solar radiation mostly affected by the improvement of shortwave radiation code in sunny days where the error of RMSE showed decreasing about $104 \mathrm{~W} / \mathrm{m}^{2}$ and 0.08 for the MBE error metric higher than rainy days where $28 \mathrm{~W} / \mathrm{m}^{2}$ for RMSE and 0.03 for MBE error metric. 
This study has identified some reasons for the simulation problem such as limitation of local meteorological station, location, and no other variables (wind speed, temperature, pressure) in the year 2015 for comparing purposes. However, this study gave a significant understanding of comparing models through only solar radiation and the results found that this improvement method can be used to predict for a long term period. This paper contributes to the improvement of solar radiation forecasting which based on WRF model coding to decreasing error forecasting. An understanding of decreasing error for solar radiation forecasting will be expected to help understanding an accurate for solar PV power generation, management, including planning for other renewable energy sources.

Finally, this paper suggests that the objective described in weather forecasting is very important in practical implications, not only for solar radiation forecasting itself but how it gave influences the experiences with other weather variables for forecasting purposes.

\section{Acknowledgements}

I would like to acknowledge valuable data of solar radiation observed data from Dr. Ruben Jeronimo Freitas as a lecture at Hera campus, Dili, Timor Leste. I would like to say thank you to the WRF model and NCEP FNL analysis data for providing free available download model and input data.

\section{Conflicts of Interest}

The author declares no conflicts of interest regarding the publication of this paper.

\section{References}

[1] Timor Leste-Explore the Undiscovered. https://www.timorleste.tl/east-timor/about/geography-climate

[2] Verbois, H., Huva, R. and Rusydi, A. (2018) Wilfred Walsh Solar Irradiance Forecasting in the Tropics Using Numerical Weather Prediction and Statistical Learning. Solar Energy, 162, 265-277. https://doi.org/10.1016/j.solener.2018.01.007

[3] Mejia, J.F., Giordano, M. and Wilcox, E. (2018) Conditional Summertime Day-Ahead Solar Irradiance Forecast. Solar Energy, 163, 610-622. https://doi.org/10.1016/j.solener.2018.01.094

[4] Zhao, J., Guo, Z.-H., Su, Z.-Y., Zhao, Z.-Y., Xiao, X. and Liu, F. (2016) An Improved Multi-Step Forecasting Model Based on WRF Ensembles and Creative Fuzzy Systems for Wind Speed. Applied Energy, 162, 808-826. https://doi.org/10.1016/j.apenergy.2015.10.145

[5] Cheng, W.Y.Y., Liu, Y.B., Bourgeois, A.J., Wu, Y.H. and Haupt, S.E. (2017) Short-Term Wind Forecast of a Data Assimilation/Weather Forecasting System with Wind Turbine Anemometer Measurement Assimilation. Renewable Energy, 107, 340-351. https://doi.org/10.1016/j.renene.2017.02.014

[6] Lara-Fanego, V., Ruiz-Arias, J.A., Pozo-Vázquez, D., Santos-Alamillos, F.J. and Tovar-Pescador, J. (2012) Evaluation of the WRF Model Solar Irradiance Forecasts in 
Andalusia (Southern Spain). Solar Energy, 86, 2200-2217. https://doi.org/10.1016/j.solener.2011.02.014

[7] Kim, C.K. and Clarkson, M. (2016) Toward Improved Solar Irradiance Forecasts: Introduction of Post-Processing to Correct the Direct Normal Irradiance from the Weather Research and Fore Casting Model. Pure Application Geophysics, 173, 1751 1763. https://doi.org/10.1007/s00024-015-1203-x

[8] Alessandrini, S., Delle Monache, L., Sperati, S. and Cervone, G. (2015) An Analog Ensemble for Short-Term Probabilistic Solar Power Forecast. Application Energy, 157, 95-110. https://doi.org/10.1016/j.apenergy.2015.08.011

[9] Deppe, A.J., Gallus, W.A. and Takle, E.S. (2013) A WRF Ensemble for Improved Wind Speed Forecasts at Turbine Height. Weather Forecast, 28, 212-228. https://doi.org/10.1175/WAF-D-11-00112.1

[10] Lorenz, E., Remund, J., Müller, S.C., Traunmüller, W., Steinmaurer, G., Pozo, D., Ruiz-Arias, J.A., Fanego, V.L., Ramirez, L., Romeo, M.G., Kurz, C., Pomares, L.M. and Guerrero, C.G. (2009) Benchmarking of Different Approaches to Forecast Solar Irradiance. 24th European Photovoltaic Solar Energy Conference, Hamburg, 21-25 September 2009, 3.

https://pdfs.semanticscholar.org/0b83/a7bd46dfb3939ee22d3fed06f677931055e5.pdf

[11] Dunlop, E.D., Wald, L. and Suri, M. (2006) Solar Energy Resource Management for Electricity Generation from Local Level to Global Scale. Nova Science Publishers Inc., Hauppauge, 205. https://hal.archives-ouvertes.fr/hal-00125639

[12] De Araujo, J.M.S. (2019) WRF Wind Speed Simulation and SAM Wind Energy Estimation: A Case Study in Dili Timor Leste. IEEE Access, 7, 35382-35393.

https://doi.org/10.1109/ACCESS.2019.2904755

[13] Skamarock, W., Klemp, J., Dudhia, J., Gill, D., Barker, D. and Duda, M. (2008) A Description of the Advanced Research WRF Version 3.

http://dx.doi.org/10.5065/D68S4MVH

[14] NCL-NCEP Website. https://rda.ucar.edu/datasets/ds083.2

[15] Notes for Running WRF with the Aerosol-Aware Thompson Scheme (mp_physics = 28). http://www2.mmm.ucar.edu/wrf/users/wrfv3.9/mp28 updated.html

[16] Iacono, M.J., Mlawer, E.J., Clough, S.A. and Morcrette, J.-J. (2000) Impact of an Improved Longwave Radiation Model, RRTM, on the Energy Budget and Thermodynamic Properties of the NCAR Community Climate Mode, CCM3. Journal of Geophysical Research Atmospheres, 105, 14873-14890. https://doi.org/10.1029/2000JD900091

[17] Hong, S.Y., Noh, Y. and Dudhia, J. (2006) A New Vertical Diffusion Package with an Explicit Treatment of Entrainment Processes. Monthly Weather Review, 134, 2318-2341. https://doi.org/10.1175/MWR3199.1

[18] Bianco, L. (2008) Surface Layer Parameterization in WRF. http://cires1.colorado.edu/science/groups/pielke/classes/at7500/Bianco SFC.pdf

[19] NCL (2018) The NCAR Command Language (Version 6.5.0).

[20] Mathieu, D., Diagne, M., Boland, J., Schmutz, N. and Lauret, P. (2014) Post-Processing of Solar Irradiance Forecasts from WRF Model at Reunion Island. Solar Energy, 105, 99-108. https://doi.org/10.1016/j.solener.2014.03.016 